\title{
Treating Obsessive Compulsive Disorder with Cognitive Behavior Therapy (CBT): A Case
} Study

\author{
Syeda Razia Bukhari ${ }^{1}$, Komal Riaz ${ }^{2}$, Amenah Rashid ${ }^{3}$
}

\section{Abstract}

The present case study is about a 23 year's old married man from a middle socioeconomic status Muslim family residing in Islamabad. He came with the signs of obsessive compulsive disorder such as obsessions, compulsions, superstitious thinking with comorbid depression, low mood, somatic complaints, anxiety, nervousness, tension, isolation and hostility. He was having these symptoms since 2006 to 2021. The present case study was conducted to assess the efficacy of cognitive behavior therapy (CBT) for individuals suffering with obsessive compulsive disorder. Case study continued for 12 sessions of cognitive behaviors therapy. 3 (1-3) sessions were conducted in initial phase, 5 sessions (4-9) were conducted in middle phase and 3 (10-12) sessions were conducted in termination phase and 2 follow up sessions after termination phase. Patient's improvement was started in middle phase of the treatment; he seemed hopeful and motivated in getting better. After the end of the middle phase, he was almost symptom free. Further at the termination phase, patient's symptoms were distinctly reduced and relapse prevention tactics were taught to him for dealing with his obsessive compulsive disorder symptoms in future. It was confirmed that CBT is an efficient therapy to treat obsessive compulsive disorder symptoms and improve well-being.

Keywords: Obsessive Compulsive Disorder, Case Study, Cognitive Behavior Therapy

Received: 18 October 2021; Revised Received: 24 November 2021; Accepted: 05 December 2021

${ }^{1}$ Assistant Professor \& Student Counselor, Faculty of Education and Social Sciences, Shaheed Zulfikar Ali Bhutto Institute of Science and Technology (SZABIST), Islamabad Campus, Pakistan.

${ }^{2} \mathrm{MS}$ Scholar, Faculty of Education and Social Sciences, Shaheed Zulfikar Ali Bhutto Institute of Science and Technology (SZABIST), Islamabad Campus, Pakistan. ${ }^{3}$ Internee Psychologist, BeeWell Hospital, Islamabad, Pakistan.

\section{Corresponding Author Email:}

dr.razia@szabist-isb.edu.pk

\section{Introduction}

Obsessive-compulsive disorder (OCD) is defined as occurrence of obsessions and compulsions. Obsessions are repeated and unrelenting thoughts, images that are experienced as distressing and unnecessary. Compulsions are recurring behaviors or psychological acts that a person feels to determine to act in response to an obsession (Leckman et al., 2010). Obsessions and compulsions symptoms present on most days and at least for successively two consecutive weeks and be source of distress (APA, 2013). Studies show that cognitive behavioral therapy (CBT) is very helpful in long term treatment of OCD (Penzel, 2000). Reassurance seeking is a technique involving others in checking rituals and usually entails involving relatives' and friends to allay obsessional doubts. CBT is designed to help patients identify negative automatic thoughts and modify these negative thoughts, resulting is less obsessions and compulsions. Cognitive restructuring serves to modify

This article is distributed under the terms of the Creative Commons Attribution Non Commercial 4.0 License (http://www.creativecommons.org/licenses/by-nc/4.0/) which permits nonCommercial use, reproduction and distribution of the work without further permission provided the original work is attributed as specified. 
patient's dysfunctional beliefs regarding excessive checking (Antony et al., 2007).

\section{The Case Study}

Mr. S. D., 23 years old married male. He is a middle-born and has five brothers and four sisters. He came with presenting complains of obsessions (obsession of key, valet, mobile either he placed at appropriate place), compulsions (do checking again and again, such as his pocket, and place where he used to put), superstitious thinking (reoccurring thoughts that some supernatural power is following, he used to check his behind again while moving forward), depression, low mood, somatic complaints (headache, pain in all body), anxiety, nervousness, tension, isolation and hostility. His symptoms were appeared watching horror movies. After watching horror movies, he experienced some superstitious things. He felt like someone is walking along with him when he goes outside. He also started to develop obsessions regarding losing and misplacing things and compulsions regarding checking different things again and again. It was frustrating for him and he started checking for keys, mobile phone, valet and other things soon after placing them in appropriate place due to which he developed obsessions and as a reaction, he used to suffer anxiety, tension and used to do these compulsive acts to reduce his anxiety. Headache and stomach problem were the some other illnesses that he had suffered till date. At present, psychological tests indicated that he has symptoms of Obsessive Compulsive Disorder (OCD). From 2006 till 20 April 2021, he went to a number of medical practitioners for the treatment of stomach related issues. He also went to psychiatric treatment but he did not get cured. However, one of his classmates told him about psychological treatment, then he visited consultant clinical psychologist for treatment. Detail Clinical Interview on the basis of DSM 5 was conducted, he was diagnosed with obsessive compulsive disorder. Further, to measure severity, intensity and frequency of obsessions and compulsions, Yale-Brown Obsessive Compulsive Scale (Y-BOCS) was used (Goodman et al., 1989). The pretest subjective reporting and scales score indicated high level of obsessions and compulsions. Depression Anxiety and Stress Scale (DASS) (Lovibond \& Lovibond, 1995) was also administered which shows high level of depression anxiety and stress.

Cognitive behavior therapy 12 sessions were conducted (1 session per week) in around 4 month duration. The treatment mainly consisted of psycho education about the symptoms of OCD and cognitive reorganization, negative automatic thoughts, thought stop technique and relaxation techniques. After 3 months of treatment, he completely recovered from obsessions and compulsions. In initial phase, pre assessment had been conducted, post assessment has been conducted after the end of middle phase. After that 2 follow up sessions had been taken in second follow up session which was the last session, follow up assessment had been conducted (See table 1).

The objectives of the first three sessions held with the client were as follows: the execution of the therapeutic contract, gathering information on the various complaints, psycho education about the treatment model being offered (CBT), and the building of a therapeutic bond. In initial phase, he showed himself to be quite unconcerned and disbelieving of the treatment, as he told since 2006, he visited a number of psychiatrists for his problem but no improvement was found. Therapist sought to motivate him in relation to the treatment. In the second phase, he participated more and managed to better describe his complaints. At the end of this session, the psychological contract was restated and it was possible to see an 
improvement in the client's level of involvement in relation to the process of therapy. Complete psycho education regarding his problem was provided. Such as relabel intrusive thoughts and urges in your own mind as obsessions and compulsions and to do so assertively. For example, train yourself to say, "I don't think or feel that my checking acts. I'm having an obsession that I misplaced things." Or, "I don't feel that I have the need to check again and again. I'm having a compulsive urge to perform the compulsion of checking" (Rosa-Alcázar et al., 2008).

In middle phase, 6 sessions had been conducted. In these sessions, relaxation training and CBT techniques were applied on client to overcome OCD. Before starting exposure response prevention (ERP) exercises, anxiety management training was done with him such as deep breathing exercise, progressive muscle relaxation exercise and guided imaginary. Still with the aim of managing anxiety, the ACALME-SE strategy created by Rangé (2001) was applied. This technique aims to promote the acceptance of the symptoms of anxiety. As he got frightened by the initial physical reactions triggered by the anxiety and would associate them with the idea of a major loss, his level of anxiety would rise even more and his symptoms would be exacerbated. Using this strategy, it was sought to instruct the client to identify and accept the initial symptoms of anxiety, thereby avoiding a worsening of the reaction. The use of anxiety management techniques was encouraged during the whole period of treatment. In these moments of anxiety, the client was asked to try to use anxiety control techniques (breathing and ACALME-SE). The client was also informed that, for each exposure exercise carried out, the anxiety triggered by the exposure situation would be lower. The ERP (Yadin et al., 2012) exercises were started and exposure was being carried out on a gradual basis. the ERP exercises were already showing results, it was sought to introduce cognitive techniques into the therapeutic process. At this moment, as a consequence of the exposure process, obsessive thoughts were materializing and becoming the focus of the intervention. Questions such as "But aren't I more relaxed about checking?" "Are you sure this is right?"; "Aren't I doing myself some harm!" and "Do you think I will really be able to do this!" became frequent during the session and enabled the process of cognitive restructuring along with thought stop techniques. Such as, stop and then reorganized that obsessional thoughts. It was thought to create a more suitable reference with regard to checking and to fear of misplacing important things, based on evidence obtained from the exposure process. At the end of the middle phase, client obsessions and compulsions had been markedly reduced. (Rosa-Alcázar et al., 2008).

In the termination phase, 3 sessions were conducted. Termination is the counselor and the client ending the therapeutic alliance. The termination stage can be as important as the initial stage in that it is the last interaction, with the counselor. In these sessions, relapse prevention strategies were taught and how to be a therapist of own self. After that, 2 follow up sessions were taken to see the client condition either he faced OCD symptoms or not. Then follow up assessment had been conducted (Raffin et al., 2009).

\section{Ethical Considerations}

Both verbal and written consent were taken from client to voluntary participate in study. He was assured about the confidentiality concerns that his information and data will be kept confidential. He was told that he had the authority to discontinue the commitment at any phase during the period of study. 


\section{Discussion/Therapeutic Outcome}

Cognitive Behavior therapy techniques helped client to challenge his thoughts, dysfunctional beliefs regarding excessive checking and modified his checking related behaviors that reinforce to overcome his anxiety. He was able to recognize his negative automatic thoughts related to compulsions. Further, his obsessions and compulsions had been reduced with the help of cognitive Behavior therapy. He formulated a rating of anxiety aggravating situations ranging from low to high level of anxiety and step by step he faced them in imagination and rate the level of anxiety systematically. His anxiety reduced from 10 to 0 , then he applied it in real situations. Gradually he become completely relaxed and he did not perform any compulsion. Thought stop technique used for eliminating and decreasing obsessional thoughts. In this technique, patient stop excessive obsessions. First of all, patients tried to stop obsessive thoughts as well as started taking long breath during this time period. He started noticing obsessional thoughts regarding losing and misplacing things and involved himself in different activities. Relaxation techniques such as relaxation exercises, deep breath exercise and control breath exercises were used to overcome his anxiety (Meyer et al., 2010). By using these strategies, patient's symptoms were completely cured (Jonsson \& Hougaard, 2009).

Thus, it is suggested that CBT is very helpful in reducing symptoms of OCD as well as helping the client throughout his life whenever he will have these issues (Borges et al., 2011).

In the light of the above findings, it is planned that mental health professionals would find better results if they consider CBT techniques while treating patients with mental disorders especially who suffering from obsessive compulsive disorder.

\section{Table 1}

Raw Scores for Pre-Posttests in 4 Months Follow up CBT Sessions $(N=1)$

\begin{tabular}{lrrr}
\hline & Pre-Test Scores & Post- Test Score & Follow Up Scores \\
\hline Y-BOCS & 38 & 12 & 6 \\
Depression & 25 & 8 & 6 \\
Anxiety & 21 & 7 & 5 \\
Stress & 22 & 13 & 10 \\
\hline
\end{tabular}




\section{Figure 1}

Graphical Representation of the Data of Pre, Post and Follow Up Scores

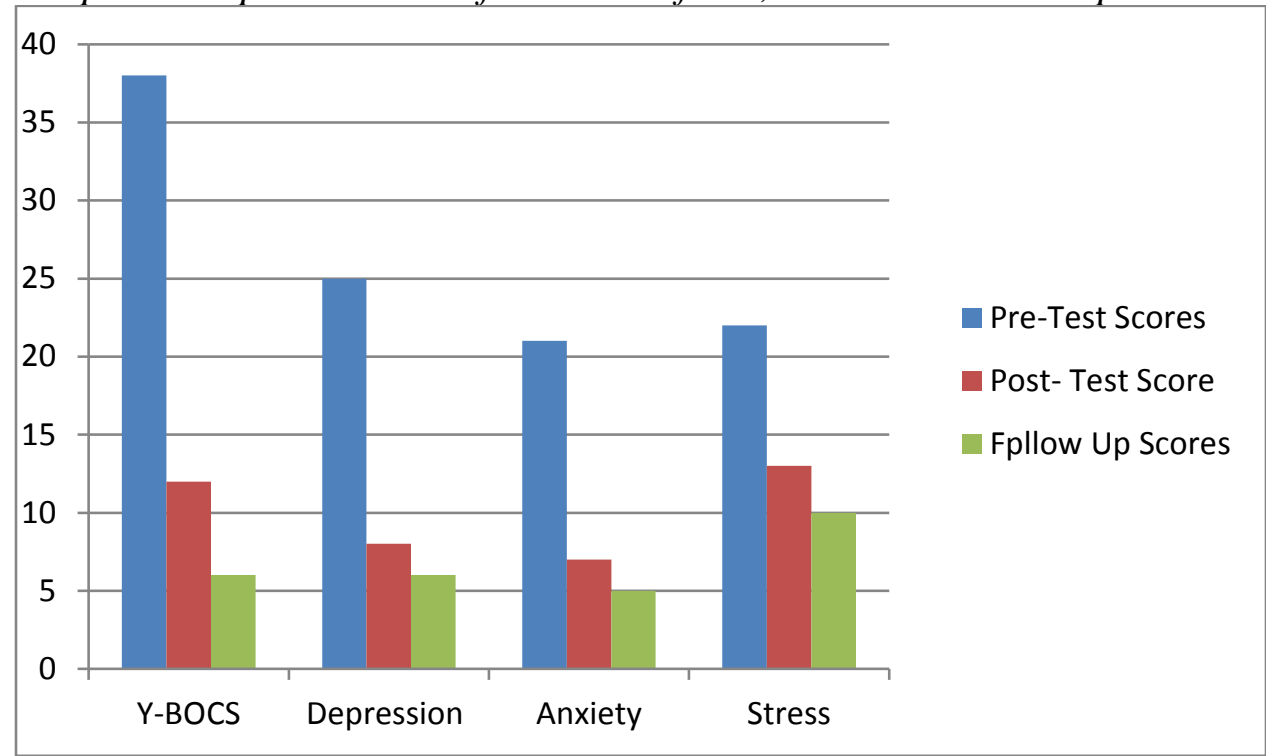

\section{References}

American Psychiatric Association (2013). Diagnostic and Statistical Manual of Mental Disorders (5th ed.). Washington, DC.

Antony, M. M., Purdon. C., \& Summerfeldt. L. J. (2007). Psychological Treatment of Obsessive-Compulsive Disorder: Fundamentals and Beyond. ( $1^{\text {st }}$ ed.). American Psychological Association: Washington.

Borges, C., Meyer, E., Ferrão, Y., Souza, F., \& Cordioli, A.V. (2011). Cognitivebehavioral group therapy versus sertraline for obsessive-compulsive disorder: five-year follow-up. Psychotherapy and Psychosomatics, 80, 249-250.

Goodman, W. K., Price, L. H., Rasmussen, S.A., Mazure, C., Fleischmann, R. L., Hill, C. L., Heninger, G. R., \& Charney, D. S. (1989). The Yale-Brown Obsessive Compulsive Scale: Archives of General Psychiatry 46(11), 1006-11.

Jonsson, H., \& Hougaard, E. (2009). Group cognitive behavioural therapy for obsessive compulsive disorder: a systematic review and meta-analysis.
Acta Psychiatrica Scandinavica, 119(2), 98-106.

Leckman, J., Denys, D., Simpson, B., MataixCols, D., Hollander, E., Saxena, S., Miguel, E., Rauch, S., Goodman, W., Phillips, K., \& Stein, D. (2010). Obsessive-compulsive disorder: a review of the diagnostic criteria and possible subtypes and dimensional specifiers for DSM-V. Depression and Anxiety, 27(6), 507-527.

Lovibond, S.H. \& Lovibond, P.F. (1995). Manual for the Depression Anxiety Stress Scales. (Second edition). Sydney: Psychological Foundation of Australia.

Meyer, E., Souza, F., Hekdt, E., Knapp, P., Cordioli, A., Shavitt, R., \& Leukefeld, C. (2010). A randomized clinical trial to examine enhancing cognitivebehavioral group therapy for obsessivecompulsive disorder with motivational interviewing and thought mapping. Behavioral and Cognitive Psychotherapy, 38(3), 319-336.

Penzel, F. (2000). Obsessive-compulsive disorders: a complete guide to getting 
well and staying well. ( $1^{\text {Ist }}$ ed.). Oxford; New York: Oxford University Press

Raffin, A., Fachel, J., Ferrão, Y., de Souza, F., \& Cordioli, A. (2009). Predictors of response to group cognitive-behavioral therapy in the treatment of obsessivecompulsive disorder. European Psychiatry, 24(5), 297-306.

Rangé, B. (2001). Transtorno do pânico e agorafobia. In B. Rangé (Ed.), Psicoterapia comportamental $e$ cognitiva de transtornos psiquiátricos (pp. 67-104). Campinas: Livro Pleno.

Rosa-Alcázar, A., Sanchez-Meca, J., GomezConesa, A., \& Marin-Martinez, F. (2008). Psychological treatment of obsessive-compulsive disorder: a metaanalysis. Clinical Psychology Review, 28(8), 1310-1325.

Yadin, E., Foa, E. B., \& Lichner, T. K. (2012). Treating Your OCD With Exposure and Response (Ritual) Prevention For Obsessive-Compulsive Disorder, Workbook, (2 ${ }^{\text {nd }}$ ed.). OUP: USA. 